\title{
Improvised condom catheter with a draining channel for management of atonic post partum haemorrhage
}

\author{
M R M Rishard ${ }^{1}$, G V M P Galgomuwa ${ }^{2}$, K Gunawardane $^{1}$ \\ (Index words: improvised device, post partum bleeding) \\ Ceylon Medical Journal 2013; 58: 124-125
}

\section{Introduction}

Primary postpartum haemorrhage $(\mathrm{PPH})$ is one of the five leading causes of maternal mortality in both developed and developing countries [1] . During the last two decades various uterine taponade devices have been used successfully in the management of PPH [2-5]. Success rates for the control of postpartum bleeding have ranged from $71 \%$ to $87 \%$ [6, 7]. So far, the Bakri balloon is the only balloon product that is specifically designed for 'the control of postpartum uterine bleeding' (Cook Medical; enclosed instruction leaflet J-SOS1106). It has a drainage lumen which allows real-time assessment of ongoing blood loss above the level of the bulb and may prevent delayed treatment. This advantage is not present in the condom catheter. We report an improvised version of the condom catheter with a draining channel which was successfully used to manage two cases of PPH with uterine atony.

\section{Method}

A large (20 Fr) folley catheter was used to inflate the condom as with any other condom catheter. A piece of the cap of a cannula $(2 \mathrm{~cm})$ was inserted through the bladder opening in the tip of the catheter and catheter balloon was perforated using a pair of scissors (Figure 1). This perforation was used to fill saline into the condom. Next a condom was inserted and it was ligated proximally and distally around the cap of the cannula. The rigid cap prevented any obstruction in the draining channel. The condom was excised distal to the ligation and the tip of the catheter was exposed (Figure 3). Next a saline drip was connected to the balloon port (the proximal valve was cut and separated before connecting to drip) and the condom was inflated (Figure 2). Alternatively a $50 \mathrm{ml}$ syringe can be used for this purpose. Once the condom was inflated, the bladder opening in the tip of the catheter drained any ongoing bleeding.

Assembling this device needs only a cap of cannula and a draining bag in addition to the usual requirements.
This device needs careful insertion by a trained person to avoid perforation and needs intermittent flushing of the draining channel to relieve potential blockage.

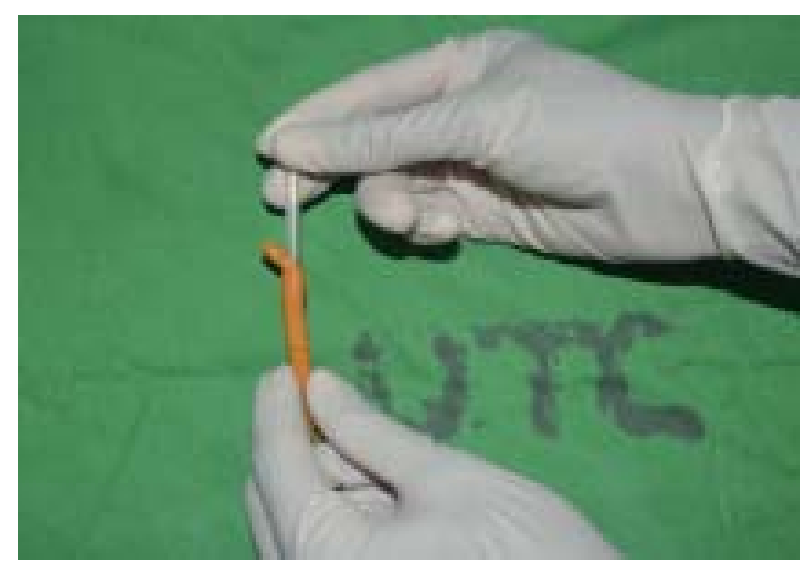

Figure 1. Cap of the canula is inserted through the opening in the tip.

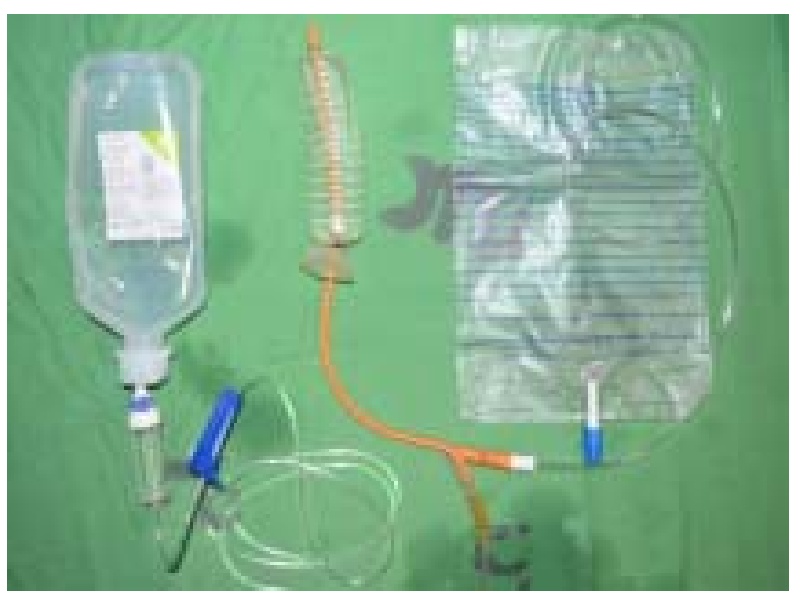

Figure 2. After inflating the condom, the draining bag is connected.

${ }^{1}$ Teaching Hospital, Kandy and ${ }^{2}$ Faculty of Medicine, University of Peradeniya, Sri Lanka.

Correspondence: MRMR, email: <rishi7875@yahoo.com>. Received 14 November 2012 and revised version accepted 17 November 2012. Competing interests: none declared. 


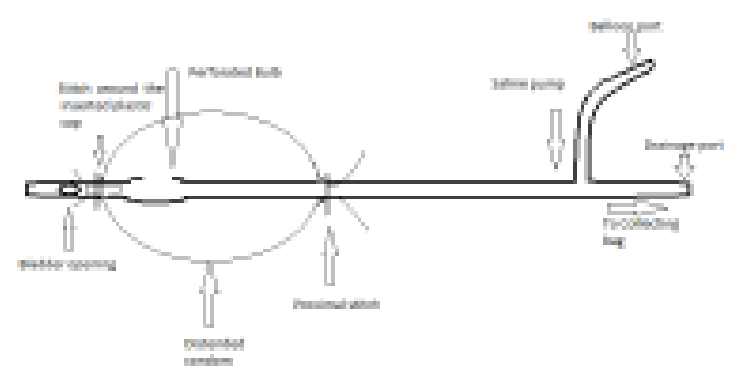

Figure 3. Outline of the improvised condom catheter.

Case 1-A 35-years old primi had lost about $600 \mathrm{ml}$ of blood after vaginal delivery. Her initial blood pressure was 100/60 mm Hg and the heart rate was 120 beats per minute. Since the uterine atony persisted despite initial management, a condom catheter with draining channel was inserted. Oxytocin infusion was continued for the next 6 hours. $20 \mathrm{ml}$ of blood drained in to the bag during the next 6 hours and she remained heamodynamically stable. The condom catheter was removed after 12 hours.

Case 2 - A 33-years old woman had continuous vaginal bleeding with an estimated blood loss of $400 \mathrm{ml}$ after a fourth vaginal delivery. After the initial management a condom catheter with draining channel was inserted. Following the successful insertion, patient's blood pressure dropped further and about $70 \mathrm{ml}$ of fresh blood collected in the draining bag. The patient was taken to the theatre for surgical management as her bleeding continued despite the tamponade.

\section{Conclusions}

The condom catheter can be improvised to monitor ongoing bleeding when the Bakry catheter is not affordable. The improvised device appears superior to the ordinary condom catheter as it creates a similar tamponade effect with the benefit of a draining channel. It is a cheaper method and our experience suggests that only an additional 3-4 minutes is required to assemble it after the learning curve. As there is a potential for delay, a senior obstetrician must always be informed beforehand. Further comparative studies are needed to evaluate the efficiency of this device.

\section{References}

1. Mousa HA, Alfirevic Z. Treatment for primary postpartum haemorrhage. Cochrane Database of Systematic Reviews 2007, Issue 1. Art. No.: CD003249.

2. Bakri YN, Amri A, Jabbar FA. Tamponade-balloon for obstetrical bleeding. International Journal of Gynaecology and Obstetrics 2001; 74: 139-42.

3. Dabelea V, Schultze PM, McDuffie RS. Intrauterine balloon tamponade in the management of postpartum hemorrhage. American Journal of Perinatology 2007; 24: 359-64

4. Johanson R, Kumar M, Obhrai M, Young P. Management of massive postpartum haemorrhage: use of a hydrostatic balloon catheter to avoid laparotomy. British Journal of Obstetrics and Gynaecology 2001; 108: 420-2

5. Akhter S, Begum MR, Kabir Z, et al. Use of a condom to control massive postpartum hemorrhage. Medscape General Medicine 2003; 5: 1-9.

6. Seror J, Allouche C, Elhaik S. Use of Sengstaken-Blakemore tube in massive postpartum hemorrhage: a series of 17 cases. Acta Obstetricia et Gynecologica Scandinavica 2005; 84: 660-4.

7. Condous GS, Arulkumaran S, Symonds I, et al. The "tamponade test" in the management of massive postpartum hemorrhage. Obstetrics and Gynaecology 2003; 101: 767-72. 